\begin{tabular}{|l|l|}
\hline $\begin{array}{l}\text { Postprint } \\
\text { Version }\end{array}$ & 1.0 \\
\hline Journal website & $\underline{\mathrm{http}: / / \text { www.thelancet.com/journals/lancet/article/PIIS0140673606681555/fullte }}$ \\
\hline Pubmed link & $\underline{\underline{\mathrm{ht}}}$ \\
\hline DOI & $10.1016 / /$ www.ncbi.nlm.nih.gov/pubmed/16473108 \\
\hline
\end{tabular}

This is a NIVEL certified Post Print, more info at http://www.nivel.eu

\title{
Somatisation: a joint responsibility of doctor and patient
}

\author{
J M BENSING, P F M VERHAAK
}

Netherlands Institute for Health Services Research, 3500 BN Utrecht, Netherlands (JMB, PFMV); and Utrecht University, Department of Health Psychology (JMB)

Patients with medically unexplained symptoms are common in general practice, 1 and frequently seen by various specialists.2 These patients are often portrayed as "difficult" or "heartsink": a burden to the doctor as well as to the health-care system,3 because they show resistance to psychological explanations of their suffering and are always in quest of biomedical causes, which easily results in excessive use of health-care services and even risk of iatrogenic harm.3 Over the years, many empirical studies have been published about this issue, but nearly all focus on patients' characteristics and roles in the process. The possibility that doctors themselves play a part in the somatising process has been largely ignored. 4

This possibility was explicitly examined by a research group from Liverpool University. ${ }^{5-7}$ Adele Ring and colleagues ${ }^{5}$ recently challenged the widespread belief of both researchers and doctors that inappropriate symptomatic treatment has to be attributed to patients' belief that symptoms are caused by physical disease, their consequent insistence on biomedical intervention, and their denial of psychosocial needs. Instead, they claim that the doctor is often responsible for the disproportionate levels of somatic interventions in this group of patients. By detailed analysis of 420 audiotaped consultations with patients with medically unexplained symptoms in general practice, the authors were able to show that physical interventions were proposed more often by doctors than by patients. Moreover, almost all patients provided cues to their psychological needs, whereas most doctors suggested that one or more physical diseases might be present. The authors conclude that the explanation for the high level of physical intervention in these patients lies in doctors' responses rather than patients' demands, and they propose that explanations for somatisation should be sought in doctor-patient interaction rather than in patients' psychopathology. ${ }^{5}$ Weighing the evidence of this study, two critical remarks have to be made. First, the doctors in this study indeed proposed a lot of biomedical interventions, but two-thirds also proposed non-medical explanations for patients' symptoms. Second, nearly $70 \%$ of the patients proposed some biomedical intervention, which is definitely higher than others have found in studies with a similar design, ${ }^{8}$ so the possibility remains that with medically unexplained symptoms both doctor and patient are more active in advocating biomedical interventions. So, the evidence for the doctor's role in the somatising process could be strengthened by a replication of this study in a controlled design.

Nevertheless, the studies of the Liverpool group deserve further attention. They appeal to an approach that used to be present in psychiatry, ${ }^{9}$ but seems to be lost in the current era of 
evidence-based medicine, which is primarily focused on patients' characteristics and diagnostic criteria, while little interest is shown in the contribution of the doctor or of the doctor-patient relationship to the results of biomedical interventions. Some circumstantial evidence supporting the findings is available. Several studies show that most doctors adapt their biomedical interventions at least partly to presumed patient preferences, while, at the same time, overestimating their patients' wish for biomedical interventions, including prescriptions and referrals, ${ }^{10}$ resulting in unnecessary and even unwanted interventions. ${ }^{11}$ So doctors' behaviour indeed might foster patients' somatic fixations. ${ }^{4}$ But before we shift the blame and shame entirely from patient to doctor, it is relevant to analyse the contribution of both parties to the process of somatisation. The truth is that both patients and doctors have a preoccupation with finding biomedical causes for the presented health problems: patients because of their existential fear of serious diseases, doctors because of their professional pride and their fear for missing a medical diagnosis with all its potential judicial consequences. Hippocrates' oath, "first of all: do no harm", seems to be replaced by a new mantra: "first of all: don't miss a medical diagnosis" and, alas, there is a certain tension between these two guiding principles. ${ }^{12}$ Another truth is that both patients and doctors are at a loss when no biomedical cause is discovered by diagnostic tests: patients because they feel humiliated and seen as malingerers; doctors because they do not feel equipped to deal effectively with medically unexplained symptoms. ${ }^{13}$ A negative test result is bad news for patient as well as doctor. No wonder that many doctors and patients together land in a spiral of unnecessary biomedical interventions and growing frustration on both sides. ${ }^{4,12}$

Choosing the opposite strategy (attribution to psychological causes) is no alternative option, as most patients feel inadequately cared for when doctors "psychologise" their bodily suffering. The only option with medically unexplained symptoms is a comprehensive biopsychosocial approach right from the start, in which a biomedical track and a psychosocial track are jointly explored, thus giving the patients confidence that all biomedical needs are rightly addressed, while at the same time the floor is open for discussing the psychosocial issues that most patients are willing to discuss at the beginning of a new illness episode, but not after all medical examinations have failed to produce positive results. For when that moment has arrived, a psychological explanation is experienced as a second-rate explanation, by which many patients feel offended and humiliated. ${ }^{14}$ How would you feel yourself?

1 Rosendal M, Olesen F, Fink P. Management of medically unexplained symptoms et al. BMJ 2005; 330: 4-5.

2 Wessely, S Nimnuan C, Sharpe M. Functional somatic syndromes: one or many? Lancet 1999, 354: 936-39.

3 Rosendal M, Fink P, Bro F, Olesen F. Somatization, heartsink patients, or functional somatic symptoms? Towards a clinical useful classification in primary health care. Scand J Prim Health Care 2005; 23: 3-10.

4 Biderman A, Yeheskel A, Herman J. Somatic fixation: the harm of healing. Soc Sci Med 2003; 56: 1135-38.

5 Ring A, Dowrick CF, Humphries GM, Davies J, Salmon P. The somatising effect of clinical consultation: What patients and doctors say and do not say when patients present medically unexplained physical symptoms. Soc Sci Med 2005; 61: 1505-15.

6 Ring A, Dowrick C, Humphris G, Salmon P. Do patients with unexplained physical symptoms pressurise general practitioners for somatic treatment? A qualitative study. BMJ 2004; 328: 1057.

7 Salmon P, Dowrick CF, Ring A, Humphris GM. Voiced but unheard agendas: qualitative analysis of the psychosocial cues that patients with unexplained symptoms present to general practitioners. Br J Gen Pract 2004; 54: 171-76. 
8 Kravitz RL, Bell RA, Azari R, Kelly-Reif S, Krupat E, Thom DH. Direct observation of requests for clinical services in office practice: what do patients want and do they get it? Arch Intern Med 2003; 163: 1673-81.

9 Balint M. The doctor, his patient and the illness. London: Pitman, 1957.

10 Little P, Dorward M, Warner G, Stephens K, Senior J, Moore M. Importance of patient pressure and perceived pressure and perceived medical need for investigations, referral and prescribing in primary care: nested observational study. BMJ 2004; 328: 444.

11 Cockburn J, Pit S. Prescribing behaviour in clinical practice: patients' expectations and doctors' perceptions of patients' expectations-a questionnaire study. BMJ 1997; 315: 520-23.

$12 \mathrm{Grol} \mathrm{R}$, ed. To heal or to harm. Prevention of somatic fixation. London: Royal College of General Practitioners, 1983.

13 Hartz AJ, Noyes R, Bentkler SE, Damiano PC, Wiollard JC, Momany ET. Unexplained symptoms in primary care: perspectives of doctors and patients. Gen Hosp Psych 2000, 22: $144-52$.

14 Malterud K. Humiliation, instead of care? Lancet 2005; 366: 785-86. 